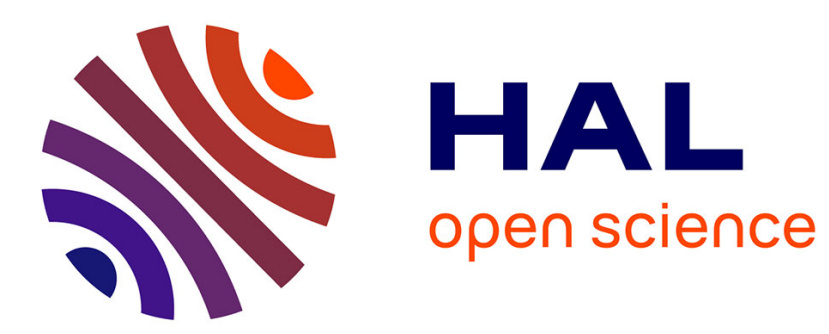

\title{
The Variations of Martensitic Morphology and Habit Plane in High Carbon Steel
}

\author{
W. Zhang, J. Ge, H. Gong, X. Zhang
}

\section{To cite this version:}

W. Zhang, J. Ge, H. Gong, X. Zhang. The Variations of Martensitic Morphology and Habit Plane in High Carbon Steel. Journal de Physique IV Proceedings, 1995, 05 (C8), pp.C8-345-C8-349. 10.1051/jp4:1995850 . jpa-00254099

\section{HAL Id: jpa-00254099 https://hal.science/jpa-00254099}

Submitted on 1 Jan 1995

HAL is a multi-disciplinary open access archive for the deposit and dissemination of scientific research documents, whether they are published or not. The documents may come from teaching and research institutions in France or abroad, or from public or private research centers.
L'archive ouverte pluridisciplinaire HAL, est destinée au dépôt et à la diffusion de documents scientifiques de niveau recherche, publiés ou non, émanant des établissements d'enseignement et de recherche français ou étrangers, des laboratoires publics ou privés. 


\title{
The Variations of Martensitic Morphology and Habit Plane in High Carbon Steel
}

\author{
W.Y. Zhang, J.P. Ge, H. Gong and X.M. Zhang* \\ Department of Materials Science and Engineering, Dalian Institute of Railway, Dalian, 116022, China \\ * Institute of Metal Research, Academia Sinica, Shenyang, 110015, China
}

\begin{abstract}
The martensites in steel T $8 \mathrm{~A}$ containing 0.8 pct $\mathrm{C}$ were examined by light microscope and TEM after martensitic austemper. There were boundary plate martensite, $\{225\}_{\gamma}$ butterfly marten-

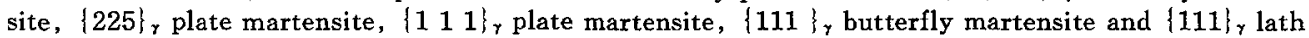
martensite observed in the steel. With the decrease of transformation temperature, the morphologies of the martensites formed changed from butterfly or plate to lath, the substructures from partial twin to dislocation and the habit planes from $\{225\}$, to $\{111\}$, . All these changes were controlled by the relief of elastic strain energy in the parent phase austenite. In a microregion of lath martensite, the martensites nucleate on two independent $\{111\}$, planes respectively, and were formed in the way of filling in. The morphology of $\{111\}_{\gamma}$ plate martensite found in this paper was similiar to that of thin plate martensite, bu it was mainly parallel and its substructure was partial twins.
\end{abstract}

\section{INTRODUCTION}

In a preceding paper, the present author[1] brought a viewpoint that the plate martensites were formed first in steel T8A, but it has not been accepted extensively by the specialized scope because the martensitic structures in steel T8A are difficult to reveal by etching and the thin films for TEM are difficult to make. Although some papers [2-4] concerning the martensites in steel $\mathrm{T} 8 \mathrm{~A}$ have been presented recenty, the systematic investigation on these martensites has not yet been made. Therefore, we try to investigate further formation process of martensites and their morphologies, substructures and changes of habit plane in steel T8A.

\section{EXPERIMENTAL PROCEDURE}

Steel T8A used in the present experiment was melted in $25 \mathrm{~kg}$ induction furnace. It was made into samples with sizes of $14 \mathrm{~mm}$ in diameter and $5 \mathrm{~mm}$ in thickness. The sample compositions (wt $\%$ ) were $0.81 \mathrm{C}, 0.34 \mathrm{Si}, 0.48 \mathrm{Mn}, 0.011 \mathrm{P}, 0.003 \mathrm{~S}, 0.01 \mathrm{Al}$ and point $\mathrm{M}_{\mathrm{s}}$ (under condition of austenization at $1200^{\circ} \mathrm{C}$ ) was $220^{\circ} \mathrm{C}$. After heating for $10 \mathrm{~min}$ at $1200^{\circ} \mathrm{C}$, the samples were quenched into a $\mathrm{Pb}-\mathrm{Sn}$ bath at $220^{\circ} \mathrm{C}, 218^{\circ} \mathrm{C}, 212^{\circ} \mathrm{C}, 209^{\circ} \mathrm{C}$ and $200^{\circ} \mathrm{C}$ for $3 \mathrm{~min}$. respectively, and then quenched into water at room temperature. Since the martensites formed during isothermal treatment at just below point $M_{s}$ can be tempered and easily colored black by etching, and the martensites formed during water quenched after isothermal treatment cannot get tempering and not readily colored by etching (maintaining white after etching), the transformation process of martensite and its morphology changes in the forming process from point $M_{s}$ to point $M_{f}$ can be distinctively revealed. The heat treated samples were mechanically polished, etched by $2 \%$ Nital and observed under light micrscope. Thin films, cut from the samples that were quenched into $10 \%$ salt water solution after austenization at $1200^{\circ} \mathrm{C}$, were thinned in $10 \%$ perchloric acid - alcohol solution at $-30^{\circ} \mathrm{C}$ and then were examined by TEM. 


\section{RESULTS and ANALYSIS}

\section{$3.1\{111\}_{\gamma}$ Plate martensite}

Of all observations, the boundary plate martensites first occured, this was in agreement with results reported in a recent paper[5]. At the same time, the large thin sheet martensites were formed on almost all original austenite grains, as shown in the upper right window of figure 1. Among these martensites, black plates formed during isothermal treatment at $218^{\circ} \mathrm{C}$ were parallel to each other in a domain. Through successive polishing method, their stereo crystal shapes were established and were similiar to the thin sheet martensite, or $\mathrm{a} \approx \mathrm{b} \gg \mathrm{c}$, with the straight $\mathrm{M} / \mathrm{A}$ boundaries. The image of this thin sheet martensite by TEM is given in figure 2 . The area located on the middle diagonal with parallel boundaries is a small block of the thin sheet martensite. The black stripes on it are partial twins (twin stripes showing wedges), the upper right window in figure 2 is a symmetric diffraction pattern of the twins. This indicates that the substructure of the thin sheet martensite is partial twins, and is totally different from the complete twin substructure of thin plate martensite.

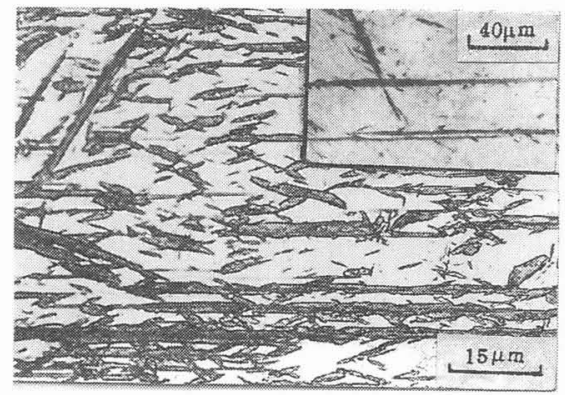

Figure 1: Changes from $\{111\}$, plate martensite to lath martensite, isothermal temperature at $209^{\circ} \mathrm{C}$ (the upper right window at $218^{\circ} \mathrm{C}$ )

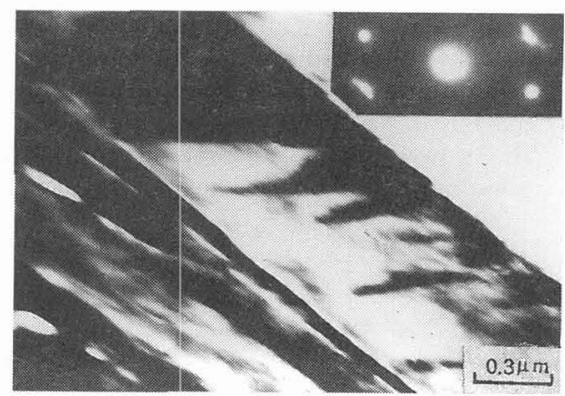

Figure 2: Electron micrograph showing $\{111\}_{\gamma}$ plate martensite. $1200^{\circ} \mathrm{C}$, quenched into $10 \%$ salt water solution

The habit plane of the thin sheet martensite, measured through the successive polishing method, was near to (111) ${ }_{\gamma}$. According to its geometric shape and substructure, we can call the thin sheet martensite $\{111\}_{\gamma}$ plate martensite.

The microstructures in figure 1 were formed before and during isothermal treatment at $209^{\circ} \mathrm{C}$. In comparison with the upper right window, in addition to increase of a few of $\{111\}_{\gamma}$ plate martensites, the lath martensites with spindle-like sections appeared. The latter sections were oriented in two directions, and their substructures were dislocations as shown in the lower left of figure 2 .

\section{$3.2\{225\}_{\text {r }}$ Plate martensite}

Figure 3 shows the martensites formed during isothermal treatment at $212^{\circ} \mathrm{C}$. The upper left window of figure 3 is a large plate martensite during isothermal treatment at $218^{\circ} \mathrm{C}$. There are also many lath martensites in addition to plate martensites, and these lath martensites appear generally in two directions. Figure 4 shows that the substructrue of large plate martensite is dislocations. According to measurement, the habit plane of the large platge martensite was near (225) y plane. This indicates that in steel T8A with the decrease of transformation temperature, the $\{225\}_{\gamma}$ plate martensites were formed first and then the lath martensites. Also their substructures changed from partial twins to dislocation. 


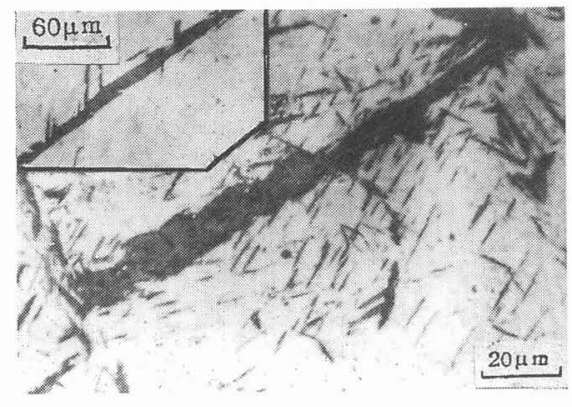

Figure 3: Changes from $\{225\}$, plate martensite to lath martensite. Isothermal temperature at $212^{\circ} \mathrm{C}$ (The upper left window, at $218^{\circ} \mathrm{C}$ )

\subsection{Martensite on austenite twin boundaries}

The upper left window of figure 5 shows that symmetric butterfly and symmetric plate martensites were formed first on austenite annealing twin boundaries, this is identical with the conclusions reported recently in the paper [5]. According to measurement, the habit planes of the butterfly martensites on annealing twin boundaries were near (1111) $\gamma$ and (111) $\gamma$ planes, but the habit plane of symmetric plate martensite has not yet been verified. Compared the lower right with the upper left of figure 5, one can find that after formation of (111) $\gamma$ butterfly martensite, the parallel $\{111\}, r$ martensites occur during isothermal treatment at $209^{\circ} \mathrm{C}$. Among these $\{111\}$, plate martensites, the lath martensites were oriented in two directions. This verifies that with the decrease of forming temperature, both $\{111\}$, butterfly martensite and $\{111\}$, plate martensite were formed first on the annealing twin boundaries and finally the lath martensite in steel T8A.

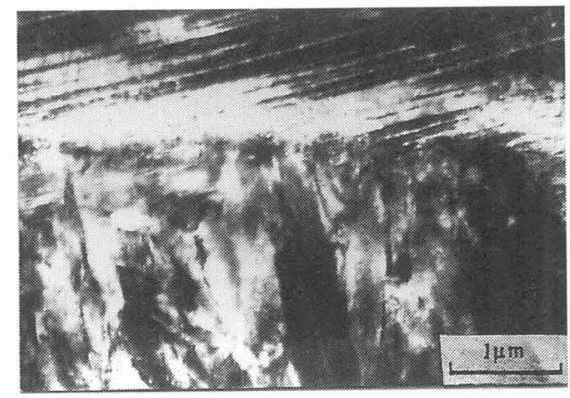

Figure 4: Electron micrograph showing $\{225\}$, plate and lath martensite. $1200^{\circ} \mathrm{C}$, quenched into $10 \%$ salt water solution

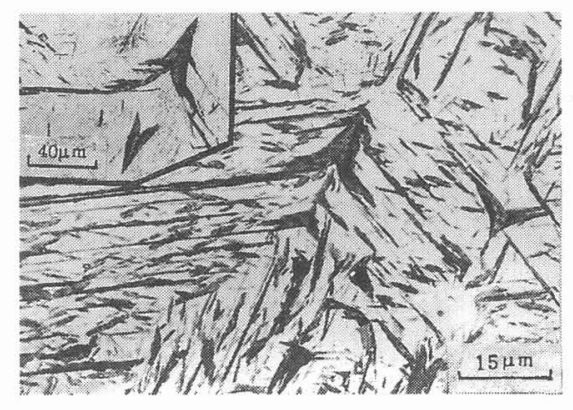

Figure 5: Changes from butterfly martensite to $\{111\}$, plate and lath martensite on austenite twin boundaries. Isothermal temperature at $209^{\circ} \mathrm{C}$ (The upper left window, at $218^{\circ} \mathrm{C}$ )

\subsection{Typical butterfly martensite}

Figure 6 and its upper left window show that the butterfly martensites without tails were formed first during isothermal treatment at $218^{\circ} \mathrm{C}$, and then the lath martensites in two directions around these butterfly martensites with the decrease of forming temperature and during isothermal treatment at $209^{\circ} \mathrm{C}$. According to measurement, the habit planes of butterfly martensites without tails were (111) $\gamma$ and (111) $\gamma$. Most substructures were dislocations but a few of the substructures were transformation twins as shown in figure 7. There were also some lath martensites arranged in triangle bundles with dislocation substructures on the left of figure 7 .

Comparison of figure 8 with its lower left window, shows that the butterfly martensites with single or double tails were formed first with the decrease of forming temperature. 


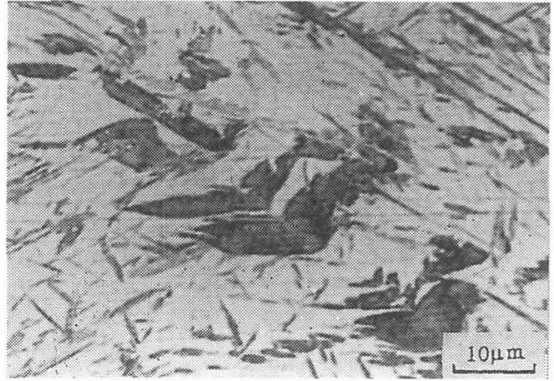

Figure 6: Changes from butterfly martensites without tails to lath martensites. Isothermal temperature at $209^{\circ} \mathrm{C}$ ( The upper left window, at $218^{\circ} \mathrm{C}$ )

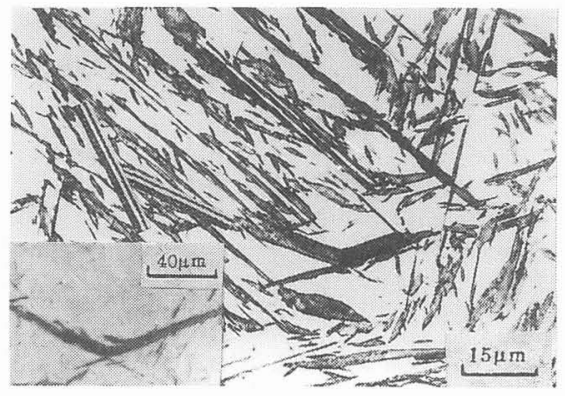

Figure 8: Changes from butterfly martensites with tails to $\{111\}$, plate martensites to lath martensite. Isothermal temperature, $200^{\circ} \mathrm{C}$ ( The down left window, at $218^{\circ} \mathrm{C}$ )

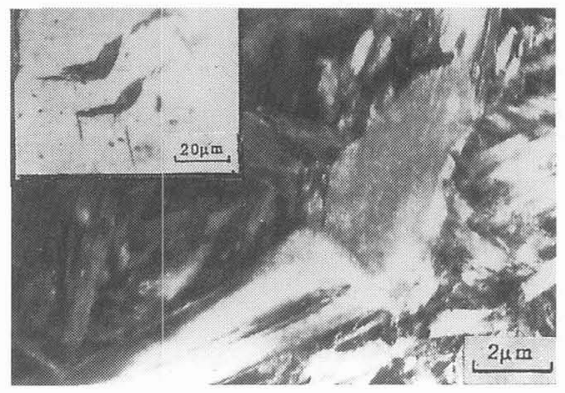

Figure 7: Electron micrograph showing butterfly martensite without tail. $1200^{\circ} \mathrm{C}$, quenched into salt water solution

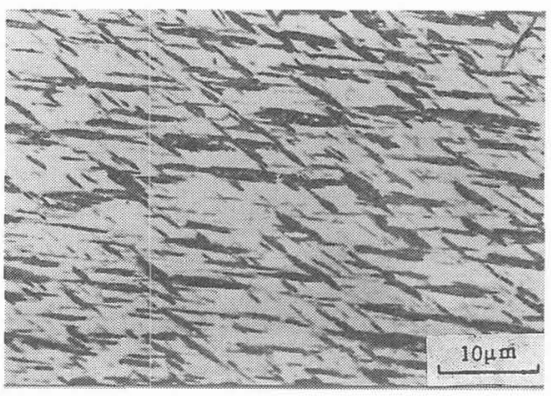

Figure 9: Thge forming process of lath martensites in steel $\mathrm{T} 8 \mathrm{~A} .1200^{\circ} \mathrm{C} \times 10 \mathrm{~min} \rightarrow 209^{\circ} \mathrm{C} \times$ $3 \mathrm{~min} \rightarrow 200^{\circ} \mathrm{C} \times 3 \mathrm{~min} \rightarrow$ quenched into water at room temperature

Their habit plane was $\{225\}_{\gamma}[6]$, subsequently, $\{225\}_{\gamma}$ plate martensite or $\{111\}_{\gamma}$ plate martensite was formed, finally the lath martensite that was distributed in two directions (shown by marking lines in figure 8 ) was formed.

\section{5 Forming process of lath martensite in steel T8A}

After austenization at $1200^{\circ} \mathrm{C}$, the sample was quenched into $\mathrm{Pb}-\mathrm{Sn}$ bath at $209^{\circ} \mathrm{C}$ for 3 min., and then into the bath at $200^{\circ} \mathrm{C}$ for $3 \mathrm{~min}$., finally into water at room temperature. Figure 9 shows a part view of the sample with all lath martensites, the lath martensites appear in two color grades: black and grey, the lath martensite of each grade is distributed in two directions. Black lath martensite was formed at $209^{\circ} \mathrm{C}$ and grey martensite at $200^{\circ} \mathrm{C}$. Between the previous formed black lath martensites, there were big areas where the grey lath martensites were filled in. Therefore, the lath martensites in steel T8A were not formed one after another (like laying bricks[7]), but were formed first on two $\{111\}$, planes respectively, and then between the formed lath martensites, new lath martensites were formed still on two other $\{111\}$, planes respectively. This forming process can be called filling in.

\section{DISCUSSION}

Professor T. Y. Hsu[8] confirmed that the state of austenite had important influence on 
martensitic transformation, and that the austenite hardening was a resistance to shear transformation. In fact, some laws obtained in this paper reveal the effects of austenite dislocation configurations (structure states) on martensitic transformation.

With the process of transformation, the elastic strain energy in the austenite was increased continuously, at same time the strain energy was also released continuously. Therefore, in the action of a long distance strain field, the dislocation density in the parent phase austenite was increased continuously. The high density of dislocation tangle prevented the development of twinning shear. As a result, a preliminary conclusion could be obtained that changes of the austenite structure state were just the reasons why the morphologies of martensite changed from butterfly or plate to lath, the substructures from partial twins to dislocations and the habit planes from high index to low index.

\section{CONCLUSIONS}

1. Aftr austenization at $1200^{\circ} \mathrm{C}$ and quenching, there will appear boundary plate martensite, $\{225\}_{\gamma}$ butterfly martensite, $(225\}_{\gamma}$ plate martensite, $\{111\}_{\gamma}$ plate martensite and $\{111\}_{\text {, lath martensite in steel T8A. }}$

2. With the decrease of forming temperature, the morphologies of martensite change from butterfly or plate to lath, the substructures from partial twins to dislocations and the habit planes from $\{225\}_{\text {, }}$ to $\{111\}_{\gamma}$ in steel $\mathrm{T} 8 \mathrm{~A}$.

3 . The changes in morphology, substructure and habit plane of the martensites are controlled by the relief of elastic strain energy in the parent phase austenite, the increase of dislocation density inhibits formation and development of twinning during martensitic transformation.

4. $\{111\}$ y plate martensite is rather a main martensite morphology in steel T8A, it is geometric shape is like thin sheet and its substructure is partial twins. Within a domain, $\{111\}$, plate martensites lay parallel each other.

5 . Within a small region in steel $\mathrm{T} 8 \mathrm{~A}$, the lath martensites nucleate on two independent $\{111\}$ y planes, and subsequent transformation occurs by filling in between these orientations.

\section{ACKNOWLEDGMENTS}

This project was financially supported by the National Nature Science Fundation of China (NSFC).

\section{REFERENCES}

[1] Gong Hai, Heat Treatment of Metals 1(1981) 10-22(in chinese).

[2] H. Gong and X. M. Zhang, Mater. Forum 14(1990) $137-141$.

[3] Gong Hai and Zhang Xiumu, China J. Met. Sci. Technol. 6(1990) 439-443

[4] Gong Hai, Advanced Research of Materials Science (Publishing House of Aviation Industry, Beijing, China, 1994)pp.55-111(in chinese)

[5] Gong Hai, Zhang Weiyi and Zhang Xiumu, Acta Metall. Sinica (English Edition), Series A 4(1991) 426-430

[6] H. Gong and N. J. Gu, Metallography 21(1988) 1-10

[7] Krauss G., Marder A. R., Met. Trans. 21(1971) 2343- 2357

[8] T. Y. Hsu, Acta Metall. Sinica (English Edition), Series A 4(1991) $386-390$ 